\title{
Electrical Conductivity of Solid and Molten Lithium Sulfate
}

\author{
Arnold Kvist and Arnold Lundén \\ Department of Physics, Chalmers Institute of Technology, Göteborg \\ (Z. Naturforschg. 20 a, 235-238 [1965]; eingegangen am 20. September 1964)
}

\begin{abstract}
The electrical conductivity of lithium sulfate has been measured over the temperature range $575-970^{\circ} \mathrm{C}$. It is found that Arrhenius equations fit the experimental data slightly less well than empirical relations, such as $\varkappa=\left(-3.297+6.894 \cdot 10^{-3} t+0.527 \cdot 10^{-6} t^{2}\right) \Omega^{-1} \mathrm{~cm}^{-1}$ for cubic $\mathrm{Li}_{2} \mathrm{SO}_{4}$ and $\quad \varkappa=\left(-13.639+35.204 \cdot 10^{-3} t-17.251 \cdot 10^{-6} t^{2}\right) \Omega^{-1} \mathrm{~cm}^{-1}$ for molten $\mathrm{Li}_{2} \mathrm{SO}_{4}$

$(t$ in degr. C) .

Due to the similarity in transport properties between cubic $\mathrm{Li}_{2} \mathrm{SO}_{4}$ and molten salts, comparisons with ionic melts are made in the discussion of our results. The ratio between the conductivity and the cation self-diffusion coefficient is less than required by the Nernst-Einstein relation, which indicates that rotation or ring mechanisms are of importance for diffusion in cubic $\mathrm{Li}_{2} \mathrm{SO}_{4}$.
\end{abstract}

Accurate data on electrical conductivity are essential for the interpretation of transport properties of ionic compounds. In connection with other investigations of cubic lithium sulfate ${ }^{1}$, we decided to remeasure its electrical conductivity, although it has been measured several times previously ${ }^{2-5}$. Many types of conductance cells have been used for measurements in molten salts; for references see recent compilations of conductivity data ${ }^{6,7}$.

Our first measurements were made in Vycor glass cells, but since these were corroded slightly by the melt, we changed to cells consisting of two concentric tubes of pure aluminium oxide (Alsint, W. $\mathrm{H}$ a l d e $\mathrm{n}$ w a n ge r, Berlin-Spandau), see Fig. 1. The lower opening of the small tube (i. d. $5 \mathrm{~mm}$ ) was clad with a hood of platinum, and a ring of platinum was placed

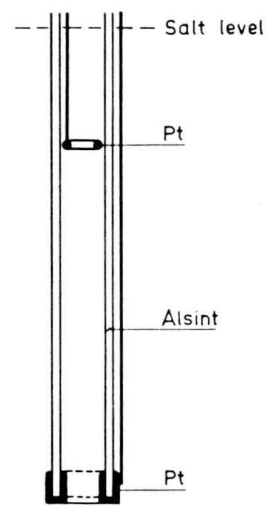

Fig. 1. Conductivity cell. The wide outer tube is excluded.

1 A. Kvist and A. LundÉn, Z. Naturforschg. 19 a, 1058 [1964].

2 A. Benrath and K. Drekopf, Z. Phys. Chem. 99, 57 [1921].

3 T. Førland and J. Krogh-Moe, private communication.

4 T. Førland and P. Reitan, private communication.

5 H. A. Ø $\varnothing_{\mathrm{YE}}$, private communication. inside this tube. The distance between the two electrodes was about $4 \mathrm{~cm}$. The cell was calibrated with $1 \mathrm{M} \mathrm{KCl}$, giving a cell constant of 20 to $30 \mathrm{~cm}^{-1}$. The cell was placed in an electrical resistance furnace, which had three separate windings: a main one, and two auxiliary ones, by means of which the vertical temperature gradient in the cell could be reduced to $0.1 \mathrm{degr} / \mathrm{cm}$ or less. An impedance bridge ( $\mathrm{R}$ a d i o m e ter, Copenhagen, type GB 11 a) was used. For each temperature, measurements were made at five different frequencies $(5,10,25,50$ and $100 \mathrm{kc} / \mathrm{s})$ and the conductivity was calculated by extrapolating to infinite frequency, according to the relation $R=R_{0}+k v^{-1 / 2}$. The change in $R$ from 5 to $100 \mathrm{kc} / \mathrm{s}$ was about $3 \%$. In aqueous solutions of many salts the frequency dependence can be reduced by using platinized electrodes,

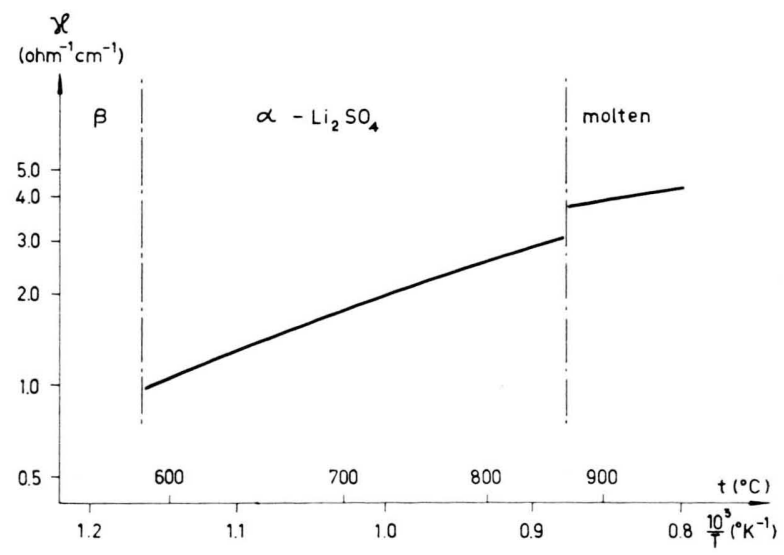

Fig. 2. Temperature dependence of conductivity for cubic and molten $\mathrm{Li}_{2} \mathrm{SO}_{4}$.

6 A. KLemm, Molten Salt Chemistry (Ed. M. Blander) Interscience Publ. Inc., New York 1964, p. 535.

7 G. J. Janz and R. D. Reeves, Adv. Electrochem. and Electrochem. Eng. V (Ed. P. Delahay and C. W. Tobias), in press. 
but we found that such electrodes could not be used in molten $\mathrm{Li}_{2} \mathrm{SO}_{4}$ (nor in $\mathrm{Li}_{2} \mathrm{MoO}_{4}$ or $\mathrm{Li}_{2} \mathrm{WO}_{4}$ ).

Reagent grade lithium sulfate $(\mathrm{Hopkin} \& \mathrm{Wil}$. li a m s AnalaR) was used without further purification. The dried salt was filled into the wide Alsint tube and melted before the narrow tube with the electrodes was inserted. Both for the melt and for the solid salt series of readings were taken with increasing as well as with decreasing temperature. The melting point $\left(860{ }^{\circ} \mathrm{C}\right)$ and the transition point $\left(575{ }^{\circ} \mathrm{C}\right)$, however, were passed only when cooling. The temperature dependence is shown in Fig. 2. Some preliminary measurements in the Vycor cell were made under an argon atmosphere, but since the results did not deviate from measurements in air, all work with the Alsint cells was done in air.

In the recent investigations by FørLand and REITAN ${ }^{4}$ and by $\varnothing_{\mathrm{YE}}{ }^{5}$ the measurements were made at lower frequencies than we used. All three investigations are in agreement regarding the general features of the temperature dependence of the conductivity, although there are systematical differences of a few per cent, FørLand and Reitan's result being lower, ØYE's being higher than ours.

The temperature dependence of electrical conductivity is often expressed by means of an Arrhenius equation $\varkappa=\varkappa_{0} \exp (-Q / R T)$, where $R$ is the gas constant, $T$ is the absolute temperature and $Q$ is interpreted as an activation energy. However, as more accurate data over extended temperature ranges have become available, it has become clear that Arrhenius equations do not give the best fit to the experimental data. Since we consider our measurements to be of good precision, we decided to test a number of empirical equations and to compute the coefficients $(A, B$, etc.) as well as their standard deviations $\left(s_{A}, s_{B} \text {, etc. }\right)^{8}$. Both linear and quadratic equations were computed:

$$
\begin{aligned}
\varkappa & =y=A_{1}+B_{1}(x-\bar{x}), \\
\varkappa & =y=A_{2}+B_{2}(x-\bar{x})+C_{2}(z-z), \\
\ln \varkappa & =y=A_{3}+B_{3}(x-\bar{x}), \\
\ln \varkappa & =y=A_{4}+B_{4}(x-\bar{x})+C_{4}(z-z)
\end{aligned}
$$

where $z=x^{2}$, and $\bar{x}$ and $\bar{z}$ are the average values of the $x$ and $z$ respectively. $x$ is here either $t \cdot 10^{-3}$ or $T^{-1} \cdot 10^{3}$ where $t=$ temperature ${ }^{\circ} \mathrm{C}$ and $T=$ temperature ${ }^{\circ}$ K. Finally, for each equation the standard deviation $s$ is calculated from

$$
s^{2}=\frac{\sum\left(\varkappa_{i}-\varkappa_{c}\right)^{2}}{n-2}
$$

where $\varkappa_{i}$ is the measured conductivity and $\varkappa_{\mathrm{c}}$ is the corresponding calculated value. $n$ is the number of measurements. Some of the obtained equations are summarized in Table $1^{9}$. For many of the equations at least one of the coefficients has a standard deviation of the same order of magnitude as the coefficient itself, which gives striking evidence to the fact that

\begin{tabular}{|c|c|c|c|c|c|c|c|c|c|c|c|c|}
\hline Eqn. & $y$ & $x$ & $z$ & $A_{i}$ & $s_{A_{i}}$ & $B_{i}$ & $s_{B_{i}}$ & $C_{i}$ & $s C_{i}$ & $\bar{x}$ & $\bar{z}$ & $s_{i}$ \\
\hline \multicolumn{13}{|c|}{ solid state } \\
\hline 1 & $x$ & $t \cdot 10^{-3}$ & - & 1.818 & 0.004 & 7.644 & 0.053 & - & - & 0.7035 & - & 0.0011 \\
\hline 2 & $x$ & $t \cdot 10^{-3}$ & $t^{2} \cdot 10^{-6}$ & 1.818 & 0.004 & 6.894 & 1.176 & 0.527 & 0.826 & 0.7035 & 0.5012 & 0.0011 \\
\hline $1^{\prime}$ & $\varkappa$ & $T^{-1} \cdot 10^{3}$ & - & 1.818 & 0.012 & -7.289 & 0.150 & - & - & 1.0306 & - & 0.0072 \\
\hline $2^{\prime}$ & $x$ & $T^{-1} \cdot 10^{3}$ & $T^{-2} \cdot 10^{6}$ & 1.818 & 0.004 & -23.462 & 1.526 & 7.856 & 7.410 & 1.0306 & 1.0689 & 0.0007 \\
\hline $3^{\prime}$ & $\ln x$ & $t \cdot 10^{-3}$ & - & 0.5396 & 0.0124 & 4.3316 & 0.1579 & - & - & 0.7035 & - & 0.0934 \\
\hline $4^{\prime}$ & $\ln x$ & $t \cdot 10^{-3}$ & $t^{2} \cdot 10^{-6}$ & 0.5396 & 0.0032 & 16.3770 & 0.8780 & -8.4715 & 0.6168 & 0.7035 & 0.5012 & 0.0166 \\
\hline 3 & $\ln x$ & $T^{-1} \cdot 10^{3}$ & - & 0.5396 & 0.0066 & -4.1665 & 0.0797 & - & - & 1.0306 & - & 0.0043 \\
\hline 4 & $\ln x$ & $T^{-1} \cdot 10^{3}$ & $T^{-2} \cdot 10^{6}$ & 0.5396 & 0.0030 & 3.9469 & 1.1310 & -3.9410 & 0.5493 & 1.0306 & 1.0689 & 0.0007 \\
\hline \multicolumn{13}{|c|}{ molten state } \\
\hline 1 & $x$ & $t \cdot 10^{-3}$ & - & 4.071 & 0.004 & 3.994 & 0.165 & - & - & 0.9020 & - & 0.0112 \\
\hline 2 & $x$ & $t \cdot 10^{-3}$ & $t^{2} \cdot 10^{-6}$ & 4.071 & 0.001 & 35.204 & 4.423 & -17.251 & 2.445 & 0.9020 & 0.8141 & 0.0021 \\
\hline 3 & $\ln x$ & $T^{-1} \cdot 10^{3}$ & - & 1.4036 & 0.0008 & -1.3595 & 0.0514 & - & - & 0.8513 & - & 0.0107 \\
\hline 4 & $\ln x$ & $T^{-1} \cdot 10^{3}$ & $T^{-2} \cdot 10^{6}$ & 1.4036 & 0.0002 & 11.3393 & 0.1860 & -7.4728 & 1.0951 & 0.8513 & 0.7250 & 0.0021 \\
\hline
\end{tabular}
an equation might fit the measured data extremely well, even if the coefficients of the individual terms are very uncertain. Thus it is often difficult to prove that e. g. apparent slight deviations from linearity

Table 1. Temperature dependence of the electrical conductivity expressed by means of the equations (1) to (4). The standard deviation $s$ is according to eqn. (5). For $\alpha-\mathrm{Li}_{2} \mathrm{SO}_{4}$ results from three independent series of measurements were used to compute the tabulated coefficients, while for the melt only one series of measurements was used. The eqns. $\left(1^{\prime}\right)$ to $\left(4^{\prime}\right)$ are given only for the solid, since they are of interest merely for a discussion of curve-fitting.

8 A. HaLd, Statistical Theory with Engineering Applications, John Wiley \& Sons, New York 1952, p. 522 and 638.
9 If the eqns. (1) to (4) are to be used for interpolation of conductivity data it is of course preferable to rewrite them as $x=a+b t+c t^{2}$, etc. 
are significant. Also, rather small deviations between the data obtained in two careful series of measurements might cause large differences between the coefficients of the two equations ${ }^{10}$. The estimation of standard deviations of the coefficients obtained by curve-fitting is tedious, but is to be recommended before the experimentally obtained coefficients are interpreted in terms of available theories.

The Arrhenius equation does not fit our measurements as well as the equations $(1),(2),\left(2^{\prime}\right)$ and (4) do. Nevertheless equation (3) is used in Table 2, where a comparison is made with previous investigations, since the "activation energy" can readily be obtained: $Q=R B$, where $B=-B_{3} \cdot 10^{3}$. The rather great spread in the $B$-values obtained from different investigations is not surprising in view of the fact that an exponential equation is considered. As has been shown previously ${ }^{11}$ it can be ambiguous, to which quantity of the salt the "activation energy" $R B$ corresponds. Therefore it is preferable to discuss $B$ instead of $Q$. It is evident that $B_{\alpha}$ is larger than $B_{\mathrm{m}}$ but smaller than $B_{\beta}$. The latter entity has not been calculated for our investigations, since the reproducibility was insufficient below the transition point. As has been pointed out by $\varnothing_{\mathrm{YE}}{ }^{5}, B$ is the physical property that changes most at the melting point, by about a factor of two ${ }^{12}$, while e. g. the change in conductivity is much less, about $28 \%$.

A rather crude determination of the cation selfdiffusion coefficient in $\alpha-\mathrm{Li}_{2} \mathrm{SO}_{4}$ has been made ${ }^{13}$, for which the $B$-value is given in Table 2 . Since in

\begin{tabular}{|c|c|c|c|c|}
\hline Investigation & $\begin{array}{c}B_{\beta} \cdot 10^{-3} \\
\text { degr. }\end{array}$ & $\begin{array}{c}B_{\alpha} \cdot 10^{-3} \\
\quad \text { degr. }\end{array}$ & $\begin{array}{c}B_{\mathrm{m}} \cdot 10^{-3} \\
\text { degr. }\end{array}$ & $\frac{\varkappa_{\mathrm{m}}}{\varkappa_{\alpha}}$ \\
\hline 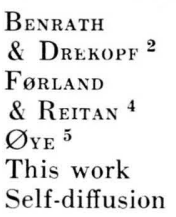 & 29 & $\begin{array}{l}5.05 \\
4.1 \\
4.17 \\
5.3\end{array}$ & $\begin{array}{l}2.75 \\
1.9 \\
1.60\end{array}$ & $\begin{array}{l}1.29 \\
1.28\end{array}$ \\
\hline
\end{tabular}

Table 2. Comparison of the temperature dependence term of the Arrhenius equation for different investigations of conductivity and for self-diffusion. The subscript $m$ denotes the molten state, and $\alpha$ and $\beta$ the two solid modifications. $\varkappa_{\mathrm{m}} / \varkappa_{\alpha}=$ conductivity ratio at the melting point.

10 See e. g. E. R. Buckle and P. E. Tsaoussoglou, J. Chem. Soc. (London) 1964, 667.

11 A. LundÉn, Z. Naturforschg. 19 a, 400 [1964]].

12 For both ØิE's and our measurements the logarithmic plot of $\varkappa$ vs $T^{-1}$ shows a pronounced negative curvature for $\alpha-\mathrm{Li}_{2} \mathrm{SO}_{4}$. In Table $2 B_{\alpha}$ is averaged over the whole temperature range. If instead the slope of the curve is estimat- many transport properties $\alpha-\mathrm{Li}_{2} \mathrm{SO}_{4}$ resembles a melt rather than an "ordinary" solid, it is instructive to discuss the interrelation of self-diffusion and conductivity for this solid in the same way as frequently is done for ionic melts. Thus, for $\alpha-\mathrm{Li}_{2} \mathrm{SO}_{4} B$ is larger for self-diffusion than for conductivity and the difference $B_{\mathrm{D}}-B_{\varkappa}$ is of the order of the absolute temperature, which Furukawa has found to hold approximately for several molten salts ${ }^{14}$; this might however be fortuitous in our case, since the standard deviation of $B_{\mathrm{D}}$ is $27 \%$.

\begin{tabular}{|c|c|c|c|}
\hline Temperature ${ }^{\circ} \mathrm{C}$ & 600 & 700 & 800 \\
\hline$\Lambda \Omega^{-1} \mathrm{~cm}^{2}$ equiv. & \\
$D^{+} \cdot 10^{5} \mathrm{~cm}^{2} \mathrm{~s}^{-1}$ & 27.3 & 47.5 & 67.9 \\
$\alpha_{+}$ & 3.54 & 6.61 & 10.99 \\
$r_{++} \cdot 10^{-15}$ for & 0.60 & 0.62 & 0.59 \\
{$\left[2 \mathrm{Li}^{+}, \mathrm{SO}_{4}^{2-}\right]$} & -2.04 & -1.11 & -0.84 \\
$r_{++} \cdot 10^{-15}$ for & 0.69 & 0.49 & 0.25 \\
{$\left[\mathrm{Li}^{+}, \mathrm{LiSO}_{4}^{-}\right]$} & 3.41 & 1.96 & 1.37 \\
$r_{+-} \cdot 10^{-15}$ for & {$\left[\mathrm{Li}^{+}, \mathrm{LiSO}_{4}^{-}\right]$} & & \\
\hline
\end{tabular}

Table 3. Transport properties of $a-\mathrm{Li}_{2} \mathrm{SO}_{4}$ : Equivalent conductivity $(\Lambda)$, cation self-diffusion coefficient $\left(D^{+}\right)$, NernstEinstein relation factor ${ }^{16}\left(\alpha_{+}\right)$, and friction coefficient ${ }^{17}\left(r_{i j}\right)$. The latter are in CGS units. The calculation of friction coefficients for the second model is oversimplified, and the results are only qualitative.

For the further discussion the equivalent conductivity $A$ is more suitable than $\varkappa$. If the density is assumed to be $2.07 \mathrm{~g} / \mathrm{cm}^{3}$ over the whole temperature range ${ }^{15}$, the equivalent conductivities given in Table 3 are obtained. The cation self-diffusion coefficients $D^{+}$are estimated from an exponential relation ${ }^{13}$. The degree of validity of the NERnst-EinSTEIN relation can be tested by calculating ${ }^{16}$

$$
\alpha_{+}=\frac{t^{+} \Lambda}{F^{2}} \frac{R T}{D^{+} z^{+}}
$$

The cation valency $z^{+}$and transport number $t^{+}$are unity ${ }^{13} \cdot \alpha_{+}$is then approx. 0.6 over the whole temperature range, while the Nernst-Einstern relation requires that $\alpha_{+}=1$. The accuracy of the $D^{+}$measurements is probably low, and the value of $\alpha_{+}$is therefore not firmly established for $\alpha-\mathrm{Li}_{2} \mathrm{SO}_{4}$, but a brief discussion may nevertheless be justified. For

ed just below the melting point $B_{a}(\mathrm{~m})$ is about $3.5 \cdot 10^{3}$ for $\varnothing_{\mathrm{YE}}$ 's and $3.0 \cdot 10^{3}$ for our measurements.

13 A. LundÉn, Z. Naturforschg. 17 a, 142 [1962].

14 K. Furukawa, Disc. Faraday Soc. 32, 53 [1961].

15 T. Førland and J. Krogh-Mof, Acta Chem. Scand. 11, 565 [1957].

16 A. Klemi, J. Chim. Phys. 60, 237 [1963]. 
several other solid salts deviations of $\alpha_{+}$from unity have been found and they may readily be explained by assuming a suitable transport mechanism ${ }^{16}$. On the other hand, if it is required that the NERNST-EINstein relation should hold (or that the correlation factor is larger than unity as required for several simple mechanisms), this leads to an "effective anion valency" less than 2 (about 1.2 for $\alpha_{+}=1$ ), which is difficult to accept from the fact that FARADAY's law holds for $\alpha-\mathrm{Li}_{2}, \mathrm{SO}_{4}$ (l. c. ${ }^{13}$ ), although models where up to half of the lithium ions are fairly tightly bound in the lattice might have some support from $\mathrm{X}$-ray studies, see below.

KLEmM has interpreted the transport properties of melts in terms of friction coefficients, which can be calculated for some simple models ${ }^{17}, 18$. The anion self-diffusion coefficient $D^{-}$has not been measured for $\alpha-\mathrm{Li}_{2} \mathrm{SO}_{4}$, but it is obvious that $D^{-} \ll D^{+}$, which means that anion-anion or anion-lattice friction coefficients are infinitely large in comparison with cationcation or cation-lattice ones. We shall consider the simplest model with two components, where only the cation-cation $\left(r_{++}\right)$and cation-anion $\left(r_{+-}\right)$friction coefficients are of interest. If complete ionization is assumed, i. e. that $\mathrm{Li}^{+}$and $\mathrm{SO}_{4}^{--}$are the sole entites, $r_{++}$becomes negative (Table 3 ), which is currently interpreted as indicating the presence of "complex ions".

According to X-ray investigations ${ }^{15,} 19$ there are three possible lattice positions available for cations per anion, i. e. one position more than the number of cations. The relative size of these positions depends on the spatial orientation of the sulfate ions ${ }^{15,19}$. It might well be that one third of the total number of positions are slightly more narrow than the others, and if we assume that a lithium ion in such a "sqeezed" position is trapped and immobile in comparison with the cations in wider positions, it is tempting to calculate friction coefficients also for other models, as done previously for molten nitrates and halides ${ }^{17,20,21}$. E. g. positive friction coefficients are obtained, see Table 3 , by a calculation for a "two-component model" with $\mathrm{Li}^{+}$and $\mathrm{LiSO}_{4}{ }^{-}$ions. However, such a treatment is oversimplified, since it is a condition for applying the friction coefficient formalism that the exchange of marked atoms (i. e.

17 A. KLemm, Z. Naturforschg. 15 a, 173 [1960].

18 A. Klem, Z. Naturforschg. 17 a, 805 [1962].

19 H. A. ØуЕ, Thesis Trondheim 1963.

20 A. Lundén, Z. Naturforschg. 15 a, 1019 [1960].
Li-atoms in our case) between the two components of the model does not contribute to self-diffusion ${ }^{18}$. Objections can be made against the likelihood of immobile cations in the salt, and another interpretation should be looked for. If all cations are assumed to be mobile, the deviation from the Nernst-Einstein relation indicates a coupled transport mechanism. Another indication of this is obtained by studying the isotope effect of electromigration, the magnitude of which is expressed by means of the mass effect $\mu$. For all investigated solid or molten salts with a high ionic conductivity it is found both that $-\mu<\frac{1}{2}$, and that $\alpha \neq 1$, while for e. $g$. $\mathrm{NaCl}-\mu_{+}=\frac{\mathrm{I}}{2}$ and $\alpha_{+}=1$ (l. c. ${ }^{16}$ ). The fact that $\alpha_{+}>1$ for $\alpha$-AgI, but $\alpha_{+}<1$ for $\alpha-\mathrm{Li}_{2} \mathrm{SO}_{4}$ and $\alpha<1$ for melts need not cause difficulties, as it is likely that the relative importance of the possible mechanisms is not the same in all salts. If the discussion now is restricted to the two solids, e. g. an indirect interstitial mechanism ${ }^{16}$ might dominate in $\alpha$-AgI, but contribute little in $\alpha-\mathrm{Li}_{2} \mathrm{SO}_{4}$. The simplest mechanism giving $\alpha=0$ is the paired vacancy one which, however, cannot be of importance when $D_{-} \ll D_{+}$. $\alpha<1$ is also obtained for ring mechanisms, where two or more ions (or vacanicies) move simultaneously round a configuration of a few sulfate ions. If a large number of lithium ions are involved in a cooperative motion in $\alpha-\mathrm{Li}_{2} \mathrm{SO}_{4}$ there might be some resemblance to the large rotating units, called globules, EgELSTAFF has introduced in a recent model of liquid diffusion ${ }^{22}$. (A similar interpretation seems also plausible for electrotransport phenomena in liquid metals ${ }^{23}$.) The cooperative transport of a fairly large number of lithium ions might to a certain extent be associated with the expected strong rotational oscillations of the sulfate ions ${ }^{19}$. Due to steric hindrance, rotation of the sulfate ions has to be strongly coupled.

This work has been supported by "Statens råd för naturforskning". We are indebted to Professor T. FøRLAND and Dr. H. A. Ø $\varnothing_{\mathrm{YE}}$ for their readiness to place their unpublished conductivity data at our disposal, to Professor A. Kцемm for valuable critisism of the manuscript, and to Mr. S. Andersson for making the computer program. We acknowledge free running time on the FACIT EDB computer, Göteborg.

21 C.-A. SJöвlom and A. LundÉn, Z. Naturforschg. 18 a, 942 [1963].

22 P. A. Egelstaff, Advances Phys. 11, 203 [1962].

23 A. Lodding, to be published. 